\title{
NK cell as a Novel Tool to Regulate and Inhibit the Progressive Growth of Tumor after Chemotherapy
}

\author{
Munendra Singh Tomar ${ }^{1}$, Sanjay Kumar ${ }^{1}$, Pramod Kumar Gautam ${ }^{2}$, Sanjay Kumar ${ }^{3}$, Rishi Kant Singh ${ }^{1}$, Praveen \\ Kumar Verma ${ }^{1}$, Surya Pratap Singh ${ }^{1}$, Amit Kumar ${ }^{1}$ and Arbind Acharya ${ }^{1 *}$
}

${ }^{1}$ Department of Zoology, Banaras Hindu University, India

${ }^{2}$ Department of Biochemistry, All India Institutes of Medical Sciences, India

${ }^{3}$ Department of Biological Sciences, Albama State University, USA

Submission: November 10, 2017; Published: November 27, 2017

*Correspondence Address: Arbind Acharya, Department of Zoology, Institute of Science, Banaras Hindu University, Varanasi, UP, India, Email: acharya@bhu.ac.in

\begin{abstract}
Natural killer Cells (NK cells) are a part of innate immune system that's play an important role as cytotoxic lymphocytes. Two types of receptors, activating (AR) and inhibitory (IR) are found on NK cells. These receptors have their specific role in the regulation of NK cells for killing the tumor cells or virus infected cells by the stimulation and secretion of cytotoxic granules containing perforin and granzyme. The functions of NK cells are inhibited by regulatory T (Treg) cells through interacting with NK cell surface receptors but the functions of these Treg cells can be modulated by some chemotherapeutic drugs like cyclophosphamide (CYP), gemcitabine, prednisolone and many more. Moreover, CYP inhibits the functions of Treg cell through various factors along with depletion of Treg cells number. Inhibition of Treg cell functions increases the activity of NK cells through modulating the expression of ARs and IRs of NK cells. Critical observation of such chemotherapeutic drugs and the regulation of NK cells on the basis of their ARs and IRs expression can be a promising chemo-immunotherapeutic approach for the treatment of cancer.
\end{abstract}

Keywords: NK cell; Activating receptors; Inhibitory Receptors; regulatory T cell; Chemotherapeutic; Cyclophosphamide

Abbreviations: NK cell: Natural Killer cells; Treg cells: Regulatory T cells; ARs: Activating Receptors; IRs: Inhibitory Receptors; CYP: Cyclophosphamide

\section{Introduction}

\section{NK Cells}

NK cells are derived from the bone marrow, identified as containing large granules, circulated in the blood and other lymphoid organs and having capability to spontaneously lyse tumor cells in vivo and in vitro without prior stimulation [1]. It is already identified that, the expression of MHC class-I molecules were down regulated or no expression on tumors cells [2]. NK cells recognize the abnormal cells on the bases of down regulation or absence of MHC I molecules (the "missing self" hypothesis) on the abnormal cells and kill them via different pathways like death receptor pathway, antibody dependent cell cytotoxicity (ADCC) pathway and perforin-granzyme mediated pathways [3]. Perforin creates the pores in tumor cells and through these pores granzymes enter into the cells and causes the cell death through apoptosis [4]. Additionally, NK cell crosstalk with DCs for antigen presentation, resulted Th1 priming and CTL mediated response for tumor cell killing. Through feedback mechanism, NK cells respond to many cytokines like IL-12, type-I IFN ( $\alpha$ and $\beta$ ), IL-2 and IL-15 released by other immune cells, which increase NK cell cytolytic, proliferative and anti-tumor functions [5].

The activation of NK cells depend on balancing signals between activating and inhibitory receptors. NK cells have another crucial role in the tumor immune surveillance in which it secrets different types of cytokines and chemokines for growth, activation and differentiation of other immune cells and their chemotaxis movement with help of their receptors [6]. They are always found to play positive role against tumor growth but the activity of NK cells may be up regulated or down regulated depends on tumor burden. It is reported that NK cell continuously work against tumor but at last stage of tumor burden the effectiveness of NK cell activity was suppressed. Generally the activity of NK cell is mainly governed by their cell surface activating or inhibitory receptors [7].

\section{NK cell Regulation}

NK cell regulation depends on many factors like involvement of different types of cytokines and chemokines and direct or 
indirect association of immune cells. They are self-capable to recognize and kill tumor cells with help of their activating and inhibitory receptors. The regulation of NK cells also depends on modulated expression of their activating and inhibitory receptors subsequently the functions of NK cells altered [8]. Besides, NK cells can kill tumor or infected cells through the activation of B cells by self-releasing IFN- $\gamma$ and TNF- $\alpha$ [9]. Subsequently, B cells produce antibodies against tumor or infected cells to eradicate them. In tumor microenvironment, NK cells secrets some regulatory molecules like IFN- $\gamma$, TNF- $\alpha$, responsible for Th1 and CTL mediated immunity for tumor lysis [10]. The suppressive effect of Treg cells on NK cells is well known and responsible for maintaining their role in autoimmunity [11]. But during the tumor progression, the activity of Treg cells were found increased due to which the activities of NK cells are suppressed [12].

The functions of NK cells are modulated due to many factors come together at the site of infection. During tumor progression, tumor cells secrets several inhibitory cytokines like TGF- $\beta$, TNF- $\alpha$, IL-6, IL-12 and many more to inhibit the functions of NK cells [13]. TGF- $\beta$ secreted at tumor microenvironment not only inhibit the NK cell functions but also inhibit the CD4+, CD8+ T cells and Dendritic cells (DCs). Treg cells inhibit the functions of NK cells by direct contact with NKG2D (AR) and through membrane bound TGF- $\beta$ on Treg cells [14]. In addition, some chemotherapeutic drugs are kwon to direct killing of tumor cells but they can also modulate the functions of immune cells including NK and Treg cells also. Further, there are several chemical compound which inhibit the activity of nTreg cells therefore may increase the effectors functions of NK cell. Anticancer drug CYP also have stringent effect on immunomodulation mediated by nTreg cells $[15,16]$.

\section{Cyclophosphamide}

Now a day's many anticancer drugs are available but their immunomodulatory effects are not completely understood. CYP is one of the well-known anticancer drugs and available as proactive form and made up of cyclic phosphamide ester of mechlorethamine [17]. The mechanism of CYP is to prevent cell division by cross linking of DNA and RNA strands. CYP have not only anti-cancer property, but also act as immunosuppressive for immuno-suppressor cells like Treg and myeloid derived suppressor (MDSCs) when used as a metronomic dose [18]. Additionally, the higher dose treatments of CYP are used for preventing graft-versus-host disease and to minimize the chance of organ rejection in organ transplantation host [19]. The vital role of CYP is to influence the immunomodulatory effects in adaptive immunotherapy as a result of decline the expression of FoxP3 as well as reduce the number of Treg cells in tumor bearing host [20].

CYP treatment depletes the number and suppresses the functions of regulatory $\mathrm{T}$ cells in tumor bearing host. Moreover, it is already reported that Treg cells suppresses the effectors functions of NK cells through NKG2D mediated cell cytotoxicity. The study about regulation of NK cell effectors functions govern directly or indirectly via CYP is a thought to be the essential part of antitumor immune response [21]. It is well known that NK cells are important cells of innate immune system and play pivotal role in the anti-tumor immune response. But during tumor progression activities of NK cells is regulated by several factors including inhibitory cytokines, immunosupressive cells like Treg cells and chemokines. During tumor progression proliferation of Treg cells effectively down regulate NK cell activities [22].

\section{Discussion}

Our findings and study will be useful for the understanding the role of chemotherapeutic drugs in the encouragement of immune cells like NK cells in the tumor immunity. This study will give a new insight vision into the chemo-immuno host relationship, which will undoubtedly expand our knowledge about the mechanism(s) adopted by immune cells and breach the immunosuppressive cells response in the tumor bearing host. Further, this study will enable us for the designing and developing a novel therapeutic/immunotherapeutic regimen directed against the transformed cells or cancer.

\section{Conclusion}

Recently, new strategies like immunotherapy have been applied and evaluated in cancer patients, but a reliable clinical response has not been successfully obtained. Regulation of this rapid first line of defence against major threats to the host will be a key to controlling immunopathogenesis and to develop novel strategies for Treg-cell-based cancer immunotherapy. After several clinical responses, it is needed to overcome the tumor escape mechanisms with designing novel strategies of combination of immunotherapy and anticancer drug treatment. One of the novel strategies will be the use of anticancer drug as an immuno-modulator too.

\section{Acknowledgement}

This work was supported by the grants from the Banaras Hindu University and University Grant Commission (UGC, P-01/669), Government of India to Prof. A. Acharya.

\section{Conflict of Interest}

The authors do not have any conflicts including financial, personal or academic interest for this manuscript.

\section{References}

1. Larsen SK, Gao Y, Basse PH (2014) NK cells in the tumor microenvironment. Crit Rev Oncog 19(1-2): 91-105.

2. Ljunggren HG, Karre K (1990) In search of the 'missing self': MHC molecules and NK cell recognition. Immunol Today 11(7): 237-244.

3. Lundqvist A, Yokoyama H, Smith A, Berg M, Childs R (2009) Bortezomib treatment and regulatory T-cell depletion enhance the antitumor effects of adoptively infused NK cells. Blood 113(24): 6120-6127. 


\section{Cancer Therapy \& Oncology International Journal}

4. Kägi D, Ledermann B, Bürki K, Seiler P, Odermatt B, et al. (1994) Cytotoxicity mediated by $\mathrm{T}$ cells and natural killercells is greatly impaired in perforin-deficient mice. Nature 369(6475): 31-37.

5. Aiba, Y, Hirayama F, Ogawa M (1997) Clonal proliferation and cytokine requirement of murine progenitors for natural killer cells. Blood 89(11): 4005-4012.

6. Waldhauer I and Steinle A (2008) NK cells and cancer immunosurveillance. Oncogene 27(45): 5932-5943.

7. Tomar MS, Kumar S, Kumar S, Gautam PK, Singh RK, et al. (2017) NK Cell Effector Functions Regulation by Modulating nTreg Cell PopulationDuring Progressive Growth of Dalton's Lymphoma in Mice. Immunol Invest 11: 1-17.

8. Middleton D, Curran M, Maxwell L (2002) Natural killer cells and their receptors. Transpl Immunol 10(2-3): 147-164.

9. Fauriat C, Long E0, Ljunggren HG, Bryceson YT (2010) Regulation of human NK-cellcytokine and chemokine production by target cell recognition. Blood 115(11): 2167-2176.

10. Klyushnenkova EN, Riabov VB, Kouiavskaia DV, Wietsma A, Zhan M, et al. (2014) Breaking immune tolerance by targeting CD25+ regulatory $\mathrm{T}$ cells is essential for the anti-tumor effect of the CTLA- 4 blockade in an HLA-DR transgenic mouse model of prostate cancer. Prostate 74(14): 1423-1432.

11. Cao Y, Zhao J, Yang Z, Cai Z, Zhang B, et al. (2010) CD4+FOXP3+ regulatory $\mathrm{T}$ cell depletion by low-dose cyclophosphamide prevents recurrence in patients with large ondylomata acuminata after laser therapy. ClinImmunol 136(1): 21-29.

12. Darrasse-Jeze G, Podsypanina K (2013) How numbers, nature, and immune status of foxp3(+) regulatory T-cells shape the early immunological events in tumor development. Front Immunol 4: 292.

13. Jewett A, Tseng HC (2011) Tumor induced inactivation of natural killer cell cytotoxic function; implication in growth, expansion and differentiation of cancer stem cells. J Cancer 2: 443-257.
14. Smyth MJ, Teng MW, Swann J, Kyparissoudis K, Godfrey DI, et al. (2006) CD4+CD25+ T regulatory cells suppress NK cell-mediated immunotherapy of cancer. J Immunol 176(3): 1582-1587.

15. Lutsiak, ME, Semnani RT, De Pascalis R, Kashmiri SV, Schlom J, et al. (2005) Inhibition of CD4(+)25+ T regulatory cell function implicated in enhanced immune response by low-dose cyclophosphamide. Blood 105(7): 2862-2868.

16. Ghiringhelli, F, Larmonier N, Schmitt E, Parcellier A, Cathelin D, et al (2004) CD4+CD25+ regulatory $\mathrm{T}$ cells suppress tumor immunity but are sensitive to cyclophosphamide which allows immunotherapy of established tumors to be curative. Eur J Immunol 34(2): 336-344.

17. Zhang, Q, Kang X, Zhao W (2006) Antiangiogenic effect of low-dose cyclophosphamide combined with ginsenoside Rg3 on Lewis lung carcinoma. Biochem Biophys Res Commun 342(3): 824-828.

18. Tongu M, Harashima N, Monma H, Inao T, Yamada T, et al. (2013) Metronomic chemotherapy with low-dose cyclophosphamide plus gemcitabine caninduce anti-tumor T cell immunity in vivo. Cancer Immunol Immunother 62(2): 383-391.

19. Luznik L, Jones RJ, Fuchs EJ (2010) High-dose cyclophosphamide for graft-versus-host disease prevention. Curr Opin Hematol 17(6): 493 499.

20. Zhao J, Cao Y, Lei Z, Yang Z, Zhang B, et al. (2010) Selective depletion of CD4+CD25+ Foxp3+ regulatory T cells by low-dose cyclophosphamide is explained by reduced intracellular ATP levels. Cancer Res 70(12): 4850-4858.

21. Man S, Bocci G, Francia G, Green SK, Jothy S, et al. (2002) Antitumor effects in mice of low-dose (metronomic) cyclophosphamide administered continuously through the drinking water. Cancer Res 62(10): 2731-2735.

22. Kerdiles Y, Ugolini S, Vivier E (2013) T cell regulation of natural killer cells. J Exp Med 210(6): 1065-1068.

Your next submission with Juniper Publishers will reach you the below assets

- Quality Editorial service

- Swift Peer Review

- Reprints availability

- E-prints Service

- Manuscript Podcast for convenient understanding

- Global attainment for your research

- Manuscript accessibility in different formats

( Pdf, E-pub, Full Text, Audio)

- Unceasing customer service

Track the below URL for one-step submission https://juniperpublishers.com/online-submission.php 